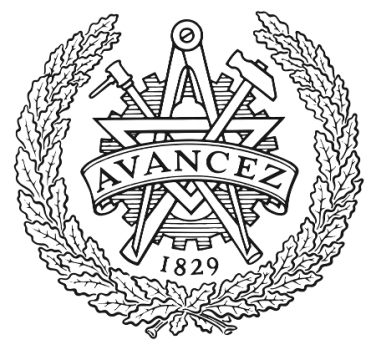

CHALMERS

UNIVERSITY OF TECHNOLOGY

\title{
Simulation-Driven Manufacturing Planning for Product-Production Variety Coordination
}

Downloaded from: https://research.chalmers.se, 2023-04-26 11:16 UTC

Citation for the original published paper (version of record):

Gong, X., Landahl, J., Johannesson, H. et al (2018). Simulation-Driven Manufacturing Planning for Product-Production Variety Coordination. IEEE International Conference on Industrial Engineering and Engineering Management: 2039-2043. http://dx.doi.org/10.1109/IEEM.2017.8290250

N.B. When citing this work, cite the original published paper. 


\title{
Simulation-Driven Manufacturing Planning for Product-Production Variety Coordination
}

\author{
X. Gong ${ }^{1}$, J. Landahl ${ }^{2}$, H. Johannesson ${ }^{2}$, R. Jiao ${ }^{1}$ \\ ${ }^{1}$ The G.W. Woodruff School of Mechanical Engineering, Georgia Institute of Technology, Atlanta, Georgia, USA \\ ${ }^{2}$ Department of Industrial and Materials Science, Chalmers University of Technology, Gothenburg, Sweden
}

(xgong45@gatech.edu)

\begin{abstract}
Ambitious manufacturers are challenged to satisfy a broad range of customers while ensuring that the emerging product variety can be produced. Current practice suggests that products and production systems are modeled separately until the late stages of development when the designs are fixed and modifications are costly. In this paper, both product and production varieties are modeled, assessed, and evaluated using discrete-event simulation during preliminary stages. An illustrative example from the aerospace industry is used to demonstrate the approach. The simulation software Simio is used to model a sequence of operations and a set of input data related to a variety of aerospace sub-systems and a variety of welding resources. Through the simulations, the average utilization rate, the average throughput time, and the average work in process are generated. These outputs are used to evaluate the sets of product-production alternatives during the early stages of platform development when the cost to adjust the design of the products, production resources and operations are trifling.
\end{abstract}

Keywords - mass customization; variety propagation; platform-based development; manufacturing plan evaluation; discrete-event simulation

\section{INTRODUCTION}

In the fierce competition among manufacturers, there is a common strive to increase market share by satisfying a wide range of customers. To accomplish this, many manufacturers have adopted a platform strategy. In this way, they can customize products for the masses based on individual customer needs while achieving mass production efficiency [1]. However, the fact that endcustomers have differing needs proves that the variety of products could be mammoth. To decrease the variety to a manageable range, the industrial platform paradigm suggests that identical components are produced and then combined into a variety of distinctive products. Thanks to the efficient utilization of production resources, the production cost can be reduced while serving a high product variety. This economy of scale in production allows manufacturers to sustain a competitive advantage [2] during the lifetime of the platform. However, other challenges come with dealing with a high product variety beyond the ability to produce and maximize the reusability of physical parts. In stages when the design engineers have a limited understanding of how the end-product will look like, what functions the constituent sub-systems will fulfill, and how these will be produced, there is a lack of support.

Current practice suggests that products and production systems are modeled separately until the late stages of development when the designs are fixed, and modifications are costly. Because of this separation, a variety of needs will propagate from both customers and production to eventually meet during the tangible production operations, see Fig. 1. The separation also expounds the lack of support for engineers from product design and pre-production to mutually model, assess, and evaluate product-production varieties in parallel when the models are immature. The importance of such parallel assessments and evaluations is elucidated by the fact that the early design decisions have a major impact on the production cost. Some research suggests that up to $85 \%$ of the production cost is tied in early phases of production design [3]. To serve as decision support to find a viable product-production variety during the early platform development phases, the integrated modeling, assessing, and evaluating across the two domains needs to be improved.

\section{A. High Variety Manufacturing Planning}

The industrial view of platforms is based on a structure of finalized designs that represents a variety of products that serves differing customer needs. Before the designs are finalized, mutual models that integrate the emerging product variety and the production resources available are rare. However, several process-focused approaches suggest integrating design and manufacturing, e.g. integrated product development [4] and concurrent engineering [5]. There are also several methods that aim to make use of production knowledge in design, such as Design for Manufacturing (DfM) and Design for Assembly (DfA) [6]. DfM and DfA have commonly been implemented to ensure that one single product can be produced utilizing the production resources available. Ensuring the producibility of a family of products has received little attention [7]. However, some work has recognized the potential to integrate product platforms and production platforms, e.g. [8,9]. There are also some examples of how to make use of DfM and DfA techniques during the platform design phases [10]. In light of this, some recent research results also suggest using a platformbased manufacturing operation model to integrate product and production varieties [11]. 


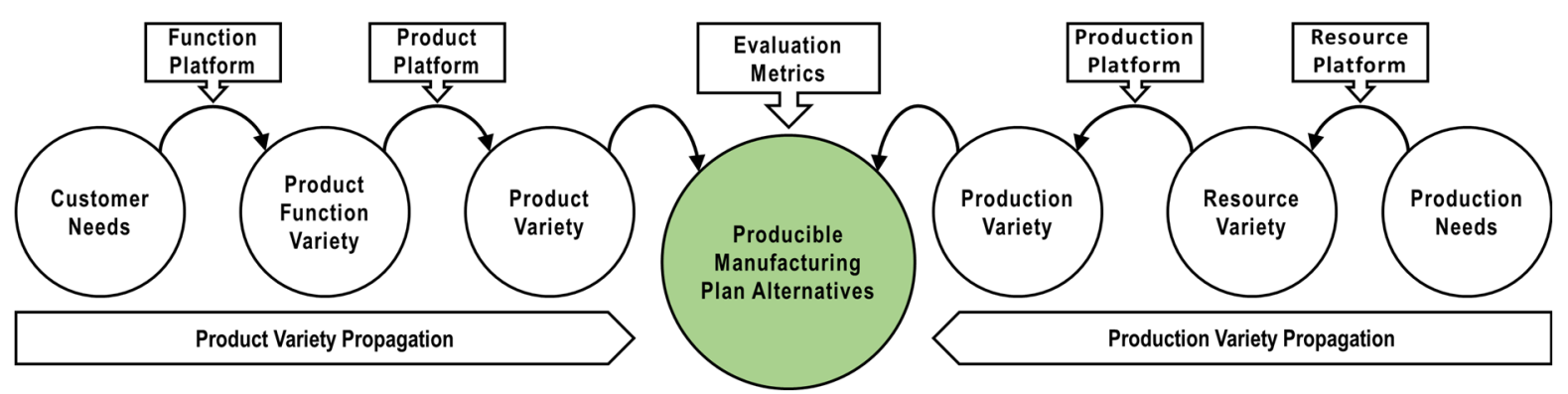

Fig. 1. Variety propagate from the product and production domains independently

This paper mainly focusses on the production part of modeling, assessing, and evaluating for coordinating an emerging variety of products and an existing variety of production resources. Fig. 1 shows how variety propagate from customer needs and production needs and culminates as manufacturing plan alternatives. The evaluation of these alternatives can be made using a set of evaluation metrics.

\section{B. Production Modeling and Simulation}

Discrete-Event Simulation (DES) can be used to imitate the operations of a real-world system by modeling the changes of state variables at a discrete set of points in time [12]. DES is a prevailing alternative to represent complex systems with stochastic elements, such as production processes [13]. To apply DES, Simio is a software broadly applied. Simio offers model-to-model transition, and the simulations can be used to derive and export various outputs [14].

To serve the simulations with conceptual models that can represent complex systems, the System Modeling Language (SysML) is commonly used [15]. SysML is a general purpose modeling language for systems engineering application. Based on XML Metadata Interchange (XMI) standard, SysML can represent a system that can be transferred to the simulation model [16]. SysML has four pillars in a series of diagrams: structure, behavior, requirement and parametric to capture several elements of complex systems.

Simulations are commonly used to verify design performance during the late development stages. However, some research proposes systematical physics-based simulations during the early stages of design to serve tradeoff studies [17]. There are also examples using a set of various simulations to assess the producibility of a product variety [18]. However, there is a dearth of research that investigates the application of simulation tools that may support the assessment of preliminary production operations that utilizes a variety of production resources to produce the same emerging product variety.

\section{Technical Approach}

This paper is aimed to support design and preproduction engineers to model, assess, and evaluate product-production varieties mutually and propel the platform development work towards the detailed development phases. In this way, it may be possible to ensure that the emerging product variety can be produced utilizing a variety of production resources available. The goal is to investigate if discrete-event simulations can support the parallel exploration of designs and production configurations towards finding producible product variants during platform concept development. To drive the work, a research question was formulated: How can discreteevent simulations support the assessment and evaluation of manufacturing plans that combines a variety of production resources and an emerging product variety during platform concept development? To answer the research question the following steps were applied: (1) Modeling of varieties; (2) Formulating evaluation metrics; and (3) Analysing the output. The next section introduces the approach with an illustrative example. The discussions and the conclusions are in the following sections, respectively.

\section{VARIETY MODELING AND SIMULATION}

\section{A. Case Study}

To demonstrate the approach, an illustrative example from the aerospace industry is presented. The company designs and manufactures components and sub-systems for commercial jet engines. The sub-systems and components come in different configurations and sizes to fit a variety of engines and aircraft. The product studied, Turbine Rear Structure (TRS), is illustrated in Fig. 2. The company seeks to reduce the time from an Original Equipment Manufacturer (OEM) request to an offer of feasible conceptual alternatives from three months to three weeks. To be increasingly efficient, they need to ensure that the design alternatives they propose are producible before closing a deal. To provide a quick response to a request, and suggest a few producible design alternatives, an anticipated product variety and the resources available therefore need to be assessed in tandem.

\section{B. Variety Modeling and Assumptions}

To represent the product variety, four different TRS variants with varying size (to fit different sizes of engines and aircraft) were assumed. None of which were modeled in detailed in this work. The product mix and the arriving rates for the product variety are shown in Table I. The four 


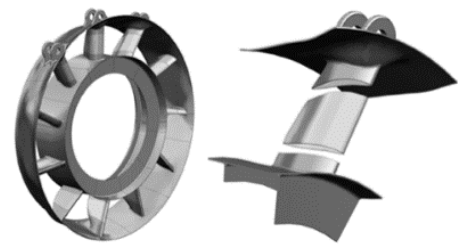

Fig. 2. The TRS divided into segments that are welded together in an assembly process

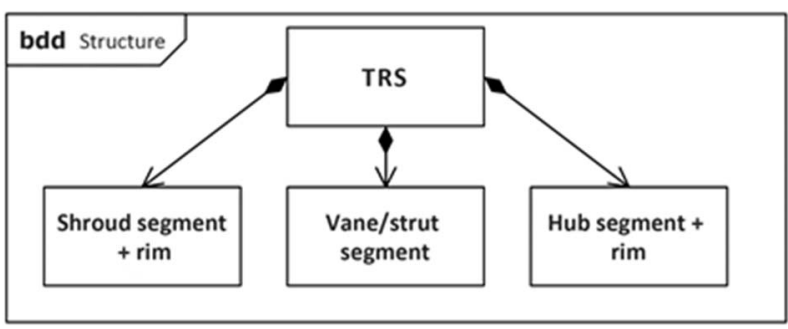

Fig. 3. The SysML model of the TRS welding assembly structure

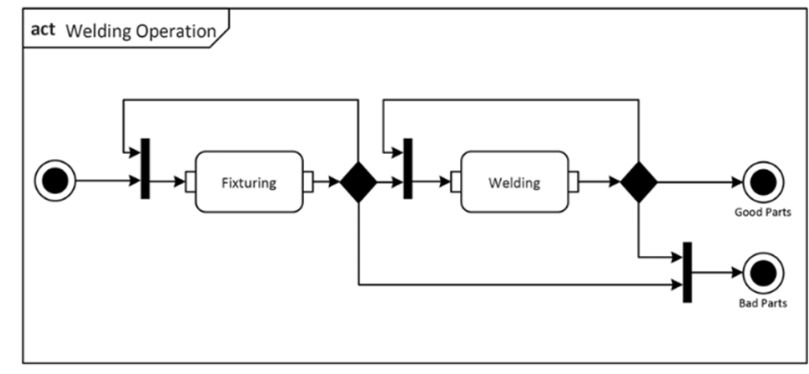

Fig. 4. The SysML model of the production process and the two main operations; fixturing and welding

TABLE I

VARIABLES OF THE PRODUCT VARIETY

\begin{tabular}{cccccc}
\hline & $\mathrm{P}_{1}$ & $\mathrm{P}_{2}$ & $\mathrm{P}_{3}$ & $\mathrm{P}_{4}$ & Total \\
\hline $\mathrm{PM}(\%)$ & 20 & 30 & 10 & 40 & 100 \\
$\mathrm{AR}(\mathrm{pcs} / \mathrm{h})$ & 0.8 & 1.2 & 0.4 & 1.6 & 4 \\
\hline
\end{tabular}

$\mathrm{PM}=$ Product mix, $\mathrm{AR}=$ Arriving rate

TABLE II

WELDING ALTERNATIVES

\begin{tabular}{ccccc}
\hline & & TIG & LBW & EBW \\
\hline & $\mathrm{P}_{1}$ & Triangular & Triangular & Triangular \\
& & $(8,11,15)$ & $(5.5,8,9.5)$ & $(6.5,8,9)$ \\
Triangular & Triangular & Triangular \\
Processing & $\mathrm{P}_{2}$ & $(7,10,13)$ & $(5,7.5,8.5)$ & $(5.5,7.5,8)$ \\
Time & & Triangular & Triangular & Triangular \\
& $\mathrm{P}_{3}$ & $(9,13,17)$ & $(6.5,9,10.5)$ & $(7,8.5,10)$ \\
& & Triangular & Triangular & Triangular \\
& $\mathrm{P}_{4}$ & $(10,14,18)$ & $(7,9.5,11)$ & $(7.5,9,10.5)$ \\
Reliability & Parts to Failure & Medium & Low & High \\
& Time to Repair & Medium & Low & High \\
\hline
\end{tabular}

TABLE III

OUTPUT DATA

\begin{tabular}{cccc}
\hline & TIG & LBW & EBW \\
\hline TT (min) & 90.9 & 54.2 & 36.2 \\
UR (\%) & 89.8 & 60.6 & 60.2 \\
WIP (pcs) & 6.05 & 3.63 & 2.42 \\
\hline
\end{tabular}

TRS variants are manufactured through welding. Based on experience, three different welding resource alternatives were assumed to handle the TRS variants: Tungsten Inert Gas (TIG) welding, Laser Beam Welding (LBW), and Electron Beam Welding (EBW). Their respective characteristics are shown in Table II. To limit the scope of the research, the production operations fixturing and welding were assumed. With the ambition to reap benefits of economies of scale, the aim is to generate producible manufacturing plans to handle the product variety utilizing the same welding resource. The generating process not only includes making trade-offs deterministically, for example accessibility of the welding tools and quality of the weld itself, but also the trade-offs based on the performance of the manufacturing plan. After the operations are reconfigured to the process routine, the trade-offs of the production system should be included. The production operations fixturing and welding were modeled using the software Simio. Each product variant that leaves an operation will be inspected and may be rejected due to inferior producibility assuming the probability of 0.1 .

In this case, the product-production varieties are modeled using SysML. A block definition diagram is applied to represent the hierarchy of the TRS welding assembly, shown in Fig. 3. The activity diagram, which is a part of behavior diagram is used to model the production process, shown in Fig. 4. The parameters of each block and actions can be attached as XMI files or sub-diagrams. Because SysML is using XMI as the data exchanging format, the models can be interpreted by Simio and translated to the simulation model. Moreover, the parameters of product design can be integrated across the product and manufacturing domains, sustaining the semantic traceability.

\section{Evaluation Metrics}

To make the producibility evaluation of the manufacturing plan alternatives that constitutes the combination of product-production varieties, metrics needs to be chosen. The general goal of the production system is to minimize the cost and maximize the responsiveness. Clearly, there is a trade-off between them. With the intention of evaluating the manufacturing plans, three performance-based evaluation metrics are used:

1) Utilization Rate (UR): UR measures the fraction of the work-centers' time, which is not idle for lacking parts. The purpose of measuring utilization is detecting the bottlenecks of the production system, or over-capacitation of resources.

2) Throughput Time (TT): TT is the average total time of the products in the system to produce the parts. The goal is to enhance the responsiveness by minimizing TT.

3) Work in Process (WIP): WIP measures the inventory along the production routing. It is a way of controlling the shop floor inventory. Thus a low WIP equals to low capital cost bound into the inventory in the production process. 


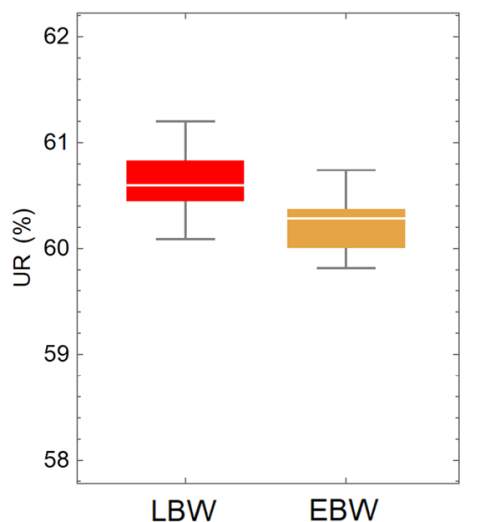

(a) Average Utilization Rates

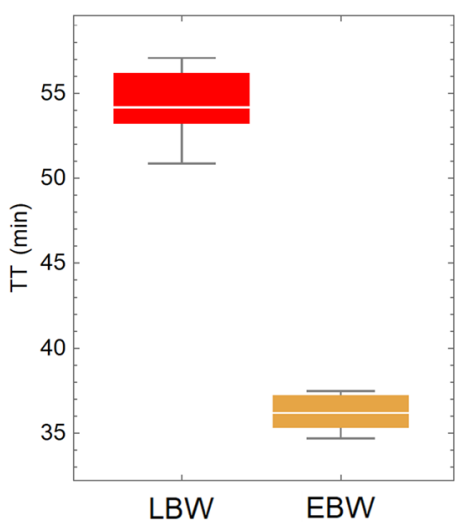

(b) Average Throughput Time

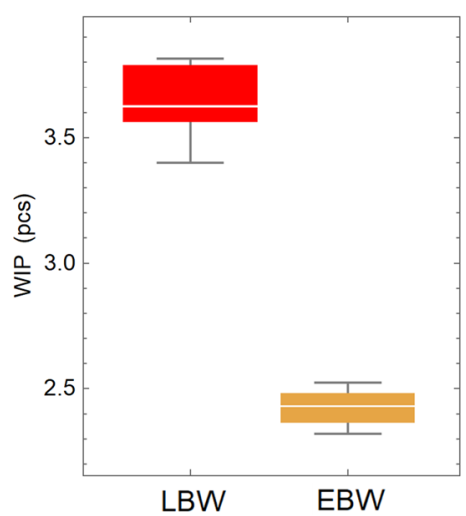

(c) Average Work in Process

Fig. 5. Box plots as an outcome of the simulations: (a) UR, (b) TT and (c) WIP.

\section{Output Analysis}

Three simulation models that includes three manufacturing plans utilizing three different welding resources are executed using the same replication of the common random numbers generated in Simio. The output data derived from each model are shown in Table III. Because of the long processing time and high processing variation, the UR, TT, and WIP of TIG welding are all high, as shown in Table III. This result shows that a manufacturing plan, utilizing TIG as the resource, is highly congested. For this reason, TIG is considered a less favorable resource for the assumed variety of the TRS.

Box plots are generated to illustrate the outputs of LBW and EBW as a basis for evaluation. As shown in Fig. 5 (a), LBW and EBW have similar utilization rates; however, due to the differences in processing variation and reliability, the TT and WIP of LBW is higher than EBW. The TT and WIP of LBW and EBW are shown in Fig. 5 (b) and (c) respectively. A high TT suggests a relatively low responsiveness because the products experience longer time in the production system throughout the process. A high WIP suggests a large inventory on the shop floor, that will lead to the indirect cost bound to the unfinished part along the routing. The manufacturing plan configured utilizing EBW has a relative higher performance compared to LBW according to the evaluation metrics provided. For this reason, EBW is the preferable welding resource. However, it is important to note that the design target is complex, and many factors are not included in this study. For example, the respective acquisition cost and the lifetime operational cost of the three welding resources are not included in this evaluation. Other important producibility aspects, such as tool accessibility or weld quality, are not explored in this study. Therefore, the result can only be regarded as a part of a broader evaluation where several trade-offs should be included. Also, the producibility of each product variant will be affected by the characteristics of each variant as well as their combination with each production resource respectively. For the preliminary stages suggested in this study, the result shall merely be regarded as a best guess of what to expect later.

\section{DISCUSSION}

To support decision making during the early development stages, current practice suggests a whole lot of guessing. To eliminate the guessing, the proposed approach may be a contribution in the way forward to increase the integration of design and manufacturing during platform concept development. The approach is useful when information about the product-production is still preliminary, as to support a direction for further advancements of the development of the emerging product variety and production variety when there is none. In this way, engineers from product design and pre-production may be supported in assessing product-production varieties.

The simplified data in Table II depicts the characteristics of the welding alternatives in relation to the product mix. This data is assumed for the specific case. Moreover, the arrival rates are based on an anticipated market demand and the current production capabilities. Because of these assumptions, the accuracy of the model may be questioned. However, the aim of this paper is to provide a novel way to bolster the parallel exploration of product-production varieties using discrete-event simulation during platform concept development. The process of evaluating the manufacturing plan alternatives aims to better coordinate the variety from the product and manufacturing domains and eliminate the inferior alternatives as early as possible.

In this study, SysML is used to manage the parameters and configurations. It offers the umberella of product and production variety modeling. Future work will be conducted to form a comprehensive strategy to support integrated variety modeling of product-production varieties. Some related research results suggest using function modeling as a technique to represent productproduction varieties, e.g. [11] and [18]. These results are currently implemented in a software - the Configurable Component Modeler (CCM). To serve several development stages, the aim is to link the function models to the SysML models. 


\section{CONCLUSION}

This paper presents an approach that integrates product and production varieties as a basis for preliminary assessments and evaluations during the early stages of platform development when modifications of the designs and the operations are still inexpensive.

Discrete-event simulation (DES) techniques are used to model a set of production operations. Each operation can accommodate a variety of production resources to produce the same emerging product variety. An illustrative case from the aerospace industry is used to demonstrate the approach. The output of the DES, includes utilization rate, throughput time, and work in process as a basis for comparison of the three manufacturing plan alternatives utilizing different welding resources. In this way, engineers from product design and pre-production may be supported in their joint goal of finding producible design alternatives during the early platform development stages.

To better support the suggested approach, future work should focus on forming of a comprehensive strategy for integrated variety modeling of product-production varieties. These preliminary models needs to enable increasingly flexible manufacturing planning capability including production resource variety and a variety of operations. The modeling of interchangeable resources, sequences should be supported. Future work also includes the implementation of the approach using the software tool CCM, as discussed above. To accomplish this, the models should accommodate rapid reconfiguration and parameter reset to serve individual customer needs as well as production needs.

\section{ACKNOWLEDGMENT}

This work was carried out at the Design Systems Engineering Lab at Georgia Institute of Technology, USA, in collaboration with the Wingquist Laboratory VINN Excellence Centre within the Area of Advance Production at Chalmers University of Technology, Sweden. The research is supported by the Swedish Governmental Agency for Innovation Systems (VINNOVA). The support is gratefully acknowledged.

\section{REFERENCES}

[1] J. R. Jiao, T. W. Simpson and Z. Siddique (2007), Product Family Design and Platform-Based Product Development: A State-of-the-Art Review, Journal of Intelligent Manufacturing, 18, 5-29

[2] M. H. Meyer, O. Osiyevskyy, D. Libaers and M. van Hugten (2017), Does Product Platforming Pay Off?, Journal of Product Innovation Management, Wiley Periodicals

[3] H. Ahlmann (2002), From Traditional Practice to the New Understanding: The Significance of the Life Cycle Profit Concept in the Management of Industrial Enterprises,
International Foundation for Reseach in Maintenance: Maintenance Management \& Modelling Conference, May 67, Växjö, Sweden

[4] M. M. Andreasen and L. Hein (1987), Integrated Product Development, New York, USA, Springer

[5] B. Prasad (1996), Concurrent Engineering Fundamentals: Integrated Product and Process Organization, Prentice Hall PTR

[6] G. Boothroyd (1994), Product Design for Manufacture and Assembly, Computer-Aided Design, 26, 505-520

[7] T. W. Simpson (2003), Product Platform Design and Optimization: Status and Promise, ASME 2003 International Design Engineering Technical Conferences and Computers and Information in Engineering Conference,

[8] J. R. Jiao, L. Zhang and S. Pokharel (2006). Process Platform and Production Configuration for Product Families. Product Platform and Product Family Design. Springer

[9] M. T. Michaelis (2013), Co-Development of Product and Manufacturing Systems Using Integrated Platform Models, $\mathrm{PhD}$ Thesis, Chalmers University of Technology, Gothenburg, Sweden

[10] F. J. Emmatty and S. P. Sarmah (2012), Modular Product Development through Platform-Based Design and Dfma, Journal of Engineering Design, 23, 696-714

[11] J. Landahl, J. Madrid, C. Levandowski, H. Johannesson, R. Söderberg and O. Isaksson (2017), Mediating Constraints across Design and Manufacturing Using Platform-Based Manufacturing Operations, 21st International Conference on Engineering Design - ICED2017, August 21-25, Vancouver, Canada

[12] J. Banks and J. S. Carson (2005), Discrete-Event System Simulation, Pearson

[13] L. Averill (2013), Simulation Modeling and Analysis, McGraw-Hill

[14] G. Thiers, T. Sprock, L. McGinnis, A. Graunke and M. Christian (2016), Automated Production System Simulations Using Commercial Off-the-Shelf Simulation Tools, Proceedings of the 2016 Winter Simulation Conference,

[15] L. McGinnis and V. Ustun (2009), A Simple Example of SysML-Driven Simulation, Winter Simulation Conference,

[16] G. Thiers (2014), A Model-Based Systems Engineering Methodology to Make Engineering Analysis of DiscreteEvent Logistics Systems More Cost-Accessible, PhD Thesis, Georgia Institute of Technology, Atlanta, USA

[17] J. V. Zweber, M. Blair, H. Kamhawi, G. Bharatram and A. Hartong (1998), Structural and Manufacturing Analysis of a Wing Using the Adaptive Modeling Language, Defense Technical Information Center

[18] J. Landahl, C. Levandowski, H. Johannesson, R. Söderberg, K. Wärmefjord, J. S. Carlson, J. Kressin, O. Isaksson and J. Vallhagen (2016), Using Product and Manufacturing System Platforms to Generate Producible Product Variants, 6th CIRP Conference on Assembly Technologies and Systems CATS2016, May 16-18, Gothenburg 